\title{
The Iodine Test for Reducing Sugars - A Safe, Quick and Easy Alternative to Copper(II) and Silver(I) Based Reagents
}

\author{
Holger Fleischer \\ Scheffold-Gymnasium, Schwaebisch Gmuend, Germany \\ *Corresponding author: fleischer@seminar-stuttgart.de \\ Received January 17, 2019; Revised February 26, 2019; Accepted March 10, 2019
}

\begin{abstract}
The reaction of Fehling's and Benedicts's test solutions with solutions of reducing sugars, e.g. glucose, is frequently misinterpreted with respect to the products formed. The tests are by no means suitable to detect aldehyde groups in organic molecules. The course of the reaction is known since long to be rather complex and the corresponding carboxylate, often assumed to be the major reaction product, does not occur at all. Both tests, as well as Tollens' test using alkaline silver(I) solution, have some drawbacks for chemistry lessons, especially in students' lab courses. The "iodine test", well established to quantitatively determine glucose, could be a suitable alternative in many cases. It allows a quick detection, even of small amounts or reducing sugars at room temperature by decolourisation of a weakly alkaline iodine-starch-solution. The test is based on several coupled equilibria, and hypoiodous acid is the oxidizing agent. The complexity of the molecular description of the reaction can easily be reduced. Hence, the iodine test is suited to set different levels of difficulty, in lab work as well as in exams. The "iodine test" can even be used in Primary School, since the necessary solutions do not represent a danger.
\end{abstract}

Keywords: iodine test, Fehling's test, Benedict's test, reducing sugars

Cite This Article: Holger Fleischer, "The Iodine Test for Reducing Sugars - A Safe, Quick and Easy Alternative to Copper(II) and Silver(I) Based Reagents." World Journal of Chemical Education, vol. 7, no. 2 (2019): 45-52. doi: 10.12691/wjce-7-2-3.

\section{Introduction}

Sugars, i.e. carbohydrates of relatively low molecular weight, are nourishing contents of quite a lot of foods. They typically have a sweet taste which is highly regarded by many consumers. Thus, sugars are not only found in foods where they naturally occur. Food producers can add a variety of sugar sources to their products in order to give them a sweet taste. Drawbacks of the consumption of too much sugar are e.g. adiposity, diabetes or caries. Hence, sweeteners became popular, which give the desired taste without causing the unwanted side-effects. Sweeteners like cyclamates taste several times sweeter than sucrose and thus only a tiny fraction of them is needed. Furthermore, they cannot be metabolized, neither by the human body nor by bacteria causing tooth decay.

As a consequence of its significance, sugars and nutrition based on sugar-containing food are subjects in School. In Primary School, pupils are usually only advised to reduce the intake of food containing added sugar or even avoid it at all. [1] A scientific inquiry approach to the subject in Primary Schools is unknown to the author. In contrast, descriptions of experiments in which pupils even in Primary School perform experiments regarding starch in food are well known. [2] Later on in High School or even undergraduate chemistry lessons, reactivity and molecular structures of simple mono- and disaccharides are typical topics. [3] A characteristic property of many sugars which is usually tested for is their behaviour to act as reducing agents. A sugar is reducing, if its molecules contain an anomeric carbon atom that is not involved in a glycosidic bond.

Fehling's or Benedict's test solutions as well as Tollens' reagent are widespread and commonly used to test for reducing sugars. Despite their frequent use, they have a few drawbacks that will be outlined first.

\section{Drawbacks of Fehling's, Benedict's and Tollens' Test}

\subsection{Necessity to Heat the Solution}

None of the three tests for reducing sugars will work quickly enough at room temperature for the purpose of a chemistry lesson. Only with fructose, the typical olive green precipitate occurred under this condition within a minute. Heating with a bath of hot water is the method-of-choice here, but the material therefore has to be provided by the teacher. Given the same temperature and concentration of sugar, Fehling's test proceeds quicker than Benedict's, which is due to the higher concentration of hydroxide ions in the former. 


\subsection{Chemical Hazards and Disposal}

Each chemistry teacher has to deal with two questions when planning an experimental lab course for the students: Can the handling of the chemicals used by the students be in any way risky for them? And how are the chemicals properly disposed?

All three reagents consist of strongly alkaline solution of heavy metal compounds. According to the Globally Harmonized System (GHS), they are classified as toxic if swallowed and irritating to skin and eye. Since they are very toxic to aquatic life, the must not be drained in the sink but have to be collected and neutralized. According to those properties, the above mentioned teacher may want to consider an alternative for Fehling's, Benedict's or Tollens' reagent in order to reduce the endangering and to safe costs for disposal.

\subsection{Interpretation of Fehling's and Benedict's Test}

Fehling's and Benedict's test for reducing sugars are frequently misinterpreted. [4,5] It was shown as early as in 1927, that glucose is not oxidized to gluconate or to gluconic acid, respectively, by alkaline solutions of copper(II)compounds. [6] In the following year, EvANS and co-workers investigated the reaction at room temperature in a weakly acidic solution. They identified glucosone i.e. 2-keto-glucose, as the primary product of the reaction. [7] It is not stable and subsequent cleavage of the $C^{1}-C^{2}$ bond is a first step of a series of fragmentation reactions. The spectrum of products seems to be rather sensitive towards temperature, $\mathrm{pH}$ and complexing agents. [8] It is usually assumed that Fehling', Benedict's and Tollens' reagents oxidize simple aldehydes to the corresponding carboxylates. Based on this assumption, the wrong conclusion for glucose is drawn, leading to the above mentioned misinterpretation. For Fehling's and Benedict's test, this assumption was experimentally checked and could not be confirmed. [9] As far as Tollens' reagent is concerned, neither the reaction product with glucose nor that with simple aldehydes has been published, to the best knowledge of the author. Thus, Fehling's and Benedict's test can be used to unequivocally identify reducing sugars. The chemistry of these reactions is but rather complex and can hardly be dealt with in detail even at the High School level.

\section{The Iodine Test}

First investigations of the oxidation of glucose by iodine in alkaline solutions date from the early 20th century. $[10,11]$ Their purpose was a quantitative analyses of glucose in natural sources. Different from the reaction with Fehling's and Benedict's test solution, glucopyranose is oxidised to $\delta$-gluconolactone (see Figure 1). The latter is hydrolysed to gluconate under alkaline conditions. $[12,13,14]$.

The presence of iodine in a weakly alkaline solution can be indicated by adding a few drops of a diluted solution of amylose ("starch"), leading to the typical blue colour. The colour disappears, if glucose is added to the solution.

The active oxidizing agent in the reaction is not iodine itself but hypoiodous acid, HOI. The latter is formed from iodine in reaction $(1)$ : $[12,13]$

$$
\mathrm{I}_{2}+\mathrm{OH}^{-} \rightleftharpoons \mathrm{I}^{-}+\mathrm{HOI}
$$

An investigation of the reaction rate at different $\mathrm{pH}$ values by INGLES und ISRAEL supported this hypothesis. The authors obtained a maximum rate at a $\mathrm{pH}$ close to $\mathrm{pK}_{\mathrm{a}}$ of HOI $(11,0)$, where $c(\mathrm{HOI})$ has its maximum as well. At higher $\mathrm{pH}, c(\mathrm{HOI})$ is lowered by reaction (2) and (3). The iodate ion formed in (3) does not oxidise glucopyranose.

$$
\begin{gathered}
\mathrm{HOI}+\mathrm{OH}^{-} \rightleftharpoons \mathrm{OI}^{-}+\mathrm{H}_{2} \mathrm{O} \\
3 \mathrm{HOI}+3 \mathrm{OH}^{-} \rightleftharpoons 2 \mathrm{I}^{-}+\mathrm{IO}_{3}{ }^{-}+3 \mathrm{H}_{2} \mathrm{O}
\end{gathered}
$$

At lower $\mathrm{pH}$-values equilibrium (1) is shifted to the left side and thus $c(\mathrm{HOI})$ is lowered as well. In order to keep the $\mathrm{pH}$-value in a narrow range close to the $\mathrm{pH}$ for a maximum reaction rate, an appropriate buffer solution should be used.

For the purpose of qualitative analyses, three different solutions are needed in order to perform an iodine test. The concentrations of iodine, sodium bicarbonate and sodium carbonate can be varied, the values given here are those used for the present work.

- Solution A: Iodine $\left(c_{0}\left(\mathrm{I}_{2}\right)=0,001 \mathrm{~mol} \cdot \mathrm{L}^{-1}\right)$ dissolved in an aqueous solution of potassium iodide $\left(c_{0}(\mathrm{KI})=0,01 \mathrm{~mol} \cdot \mathrm{L}^{-1}\right)$.

- Solution B: Buffer solution of sodium carbonate $\left(\mathrm{c}_{0}\left(\mathrm{Na}_{2} \mathrm{CO}_{3}\right)=0,25 \mathrm{~mol} \cdot \mathrm{L}^{-1}\right)$ and sodium bicarbonate $\left(\mathrm{c}_{0}\left(\mathrm{NaHCO}_{3}\right)=0,25 \mathrm{~mol} \cdot \mathrm{L}^{-1}\right)$ in water.

- Solution C: Solution of soluble starch in water, $\mathrm{w}($ starch $)=0,1 \%$.

The iodine test is positive not only for reducing sugars. Several other compounds react with the iodine or the hypoiodous acid. The most prominent are given here:

- Ascorbic acid

- Ethanol

- Acetone and other ketones whose molecules contain $\mathrm{C}-\mathrm{H}$ bonds at an $\alpha$-carbon atom.

- Unsaturated compounds, especially unsaturated fatty acids.
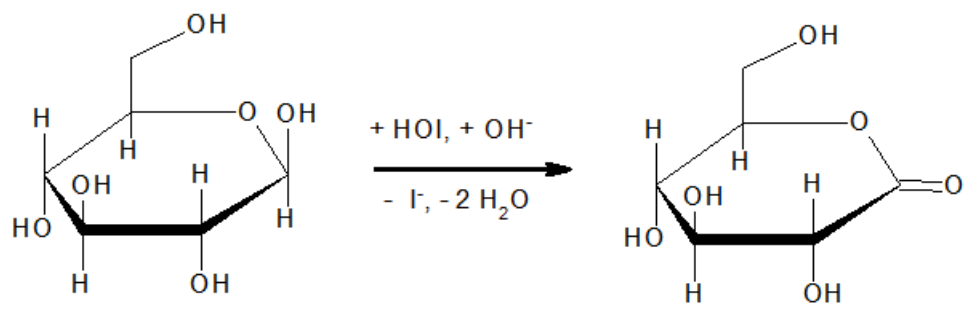

Figure 1. Oxidation of D-gluconopyranose to D- $\delta$-gluconolactone by hypoiodous acid 


\section{Pedagogical and Methodological Objectives}

The reaction of glucose and also of other reducing sugars with a weakly alkaline solution of iodine is a versatile tool, offering a variety of useful applications to chemistry in School classes and even undergraduate University courses. Its main advantages over Fehling's and Benedict's test are:

- No solutions with extreme $\mathrm{pH}$ or such containing heavy metal compounds are necessary. If direct contact with the eyes is avoided and it is not swallowed, the iodine test solution is harmless.

- The reaction proceeds rapid enough even at room temperature, so no additional heating is necessary. Hence, no glassware is needed. Simple small beakers made of plastics are suitable reaction vessels.

It is these two properties, which render the iodine test suitable even for a use in Primary School, where different foods can be tested for reducing sugars (see 4.1).

At the High School level, reducing and non-reducing sugars can be distinguished. The reaction, following a simple and straightforward stoichiometry (see Figure 1), can be understood at that level. Also, hydrolysis of the glycosidic bond in sucrose can be investigated. As well, the increase of the rate of a chemical reaction with increasing concentration of temperature can be easily deduced. Finally, the positive iodine test of a solution of fructose, a ketose, and its reduced rate can be rationalized in terms of the DE BRUYN-VAN EKENSTEIN-rearrangement. [15]

\subsection{The Iodine Test in Primary School}

According to Piaget's theory of cognitive development, pupils in Primary School are in the so called concrete operational stage. [16] They develop logical thinking, which is a prerequisite for every scientific enquiry. Regarding the enquiries presented, $4^{\text {th }}$ to $6^{\text {th }}$ year Primary School kids should be capable to understand a logical conclusion of the following, formal type: If $A \Rightarrow B$, then $-\mathrm{B} \Rightarrow-\mathrm{A}$. A is "Solution X contains grape sugar". $\mathrm{B}$ is "A weakly alkaline solution of iodine and starch that is added to solution X, becomes colourless." Hence, the kids should be able to tell, if a solution does not contain grape sugar. It might be a challenge to avoid that pupils conclude A from B. I.e. they might regard a positive iodine test as a proof for the presence of grape sugar. In that case, the iodine test with ascorbic acid or malt sugar can demonstrate, that other compounds can be the cause for decolourisation as well. Two experiments are proposed for the above mentioned purpose.

Experiment 1: A problem to start with could be the following "Some chewing gums are good for keeping teeth healthy but others are said to be harmful. The healthy ones are free of sugar, but all chewing gums taste sweet. How can we distinguish between them without tasting?" The iodine test has to be presented and Figure 2 shows the results. Experimental details are given in Chapter 5.

The kids are instructed to observe the different behaviour of a chewing gum containing sugar compared to the sugar-free chewing gum. It should become clear to them, that only the sugar containing chewing-gum will lead to a decolourization of the iodine test solution. In a second stage, they should use the test to experimentally recognize sugar-containing chewing gum.

Experiment 2: Is it table sugar that gives ripe grapes a sweet taste? The iodine test allows a distinction between table sugar and grape sugar. The former is a non-reducing sugar, i.e. the test-solution will stay blue when table sugar is added to it. In contrast, if grape juice from ripe grapes is added, the blue colour will rapidly disappear. The same happens, if grape sugar is added.
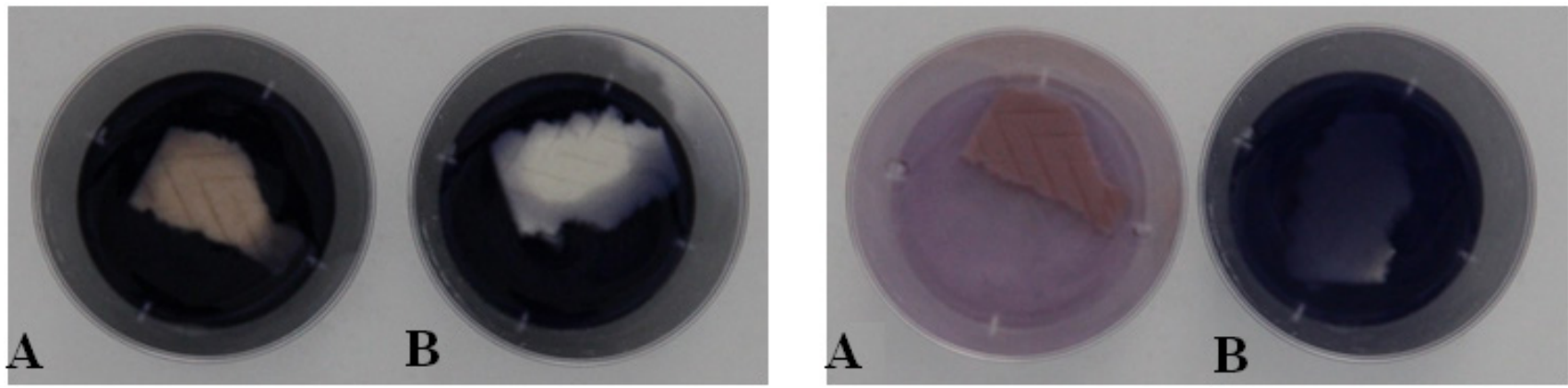

Figure 2. The iodine test with chewing gum containing sugar (A) and without sugar (B). Left: just after chewing gums were added. Right: after 5 minutes

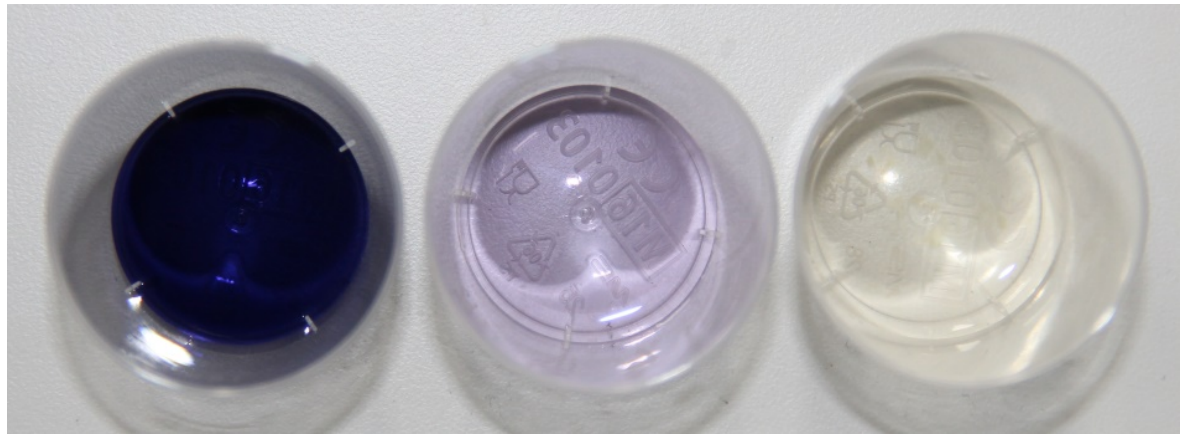

Figure 3. The iodine test with table sugar (left), grape sugar (middle) and grape juice, one minute after adding them to the iodine test solution. 
The kids should deduce from their observations that the sweet taste of the grapes cannot be caused by table sugar only. Instead, that is what they have to be told, grapes contain grape sugar. At this stage, kids can come up with the conclusion, that chewing gums cannot contain only table-sugar.

\subsection{The iodine test in High School}

Students at High School should be able to master a more abstract view on the chemistry of simple carbohydrates. Given the name of the compound, they are supposed to deduce the correct Fischer or Haworth formula (Figure 4) of the mono- and disaccharides.
Subsequently, they have to decide by the criterion of a present hemiacetal group, whether it is a reducing or a non-reducing carbohydrate.

In a simplified way, the reaction of a reducing sugar with the iodine test solution (see Figure 1) could be presented with the iodine molecule as the oxidizing agent, the hydroxide ion acting just as proton acceptor.

Experiment 3: Reducing and non-reducing sugars. The four carbohydrates given in Figure 4 are tested for their reducing action. 1, 2 and $\mathbf{3}$ will lead to a rather quick decolourization of the iodine test solution, as forecasted on the basis of the molecular structures. 4 does not change the blue colour of the solution, since sucrose is a nonreducing sugar.

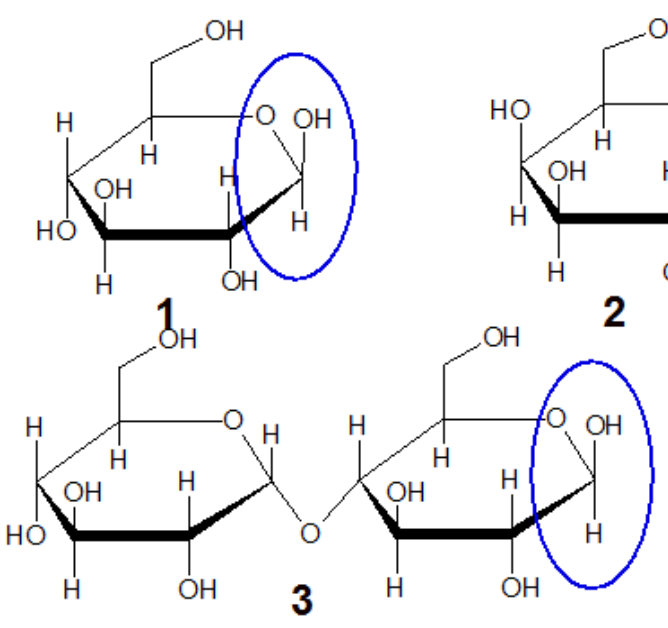

Figure 4. Haworth formula of selected monosaccharides (1 and 2) and disaccharides (3 and 4). (1: $\beta$-D-glucopyranose; 2: $\alpha$-D-galactopyranose; 3 : maltose; 4: sucrose. Hemiacetal-groups are marked)
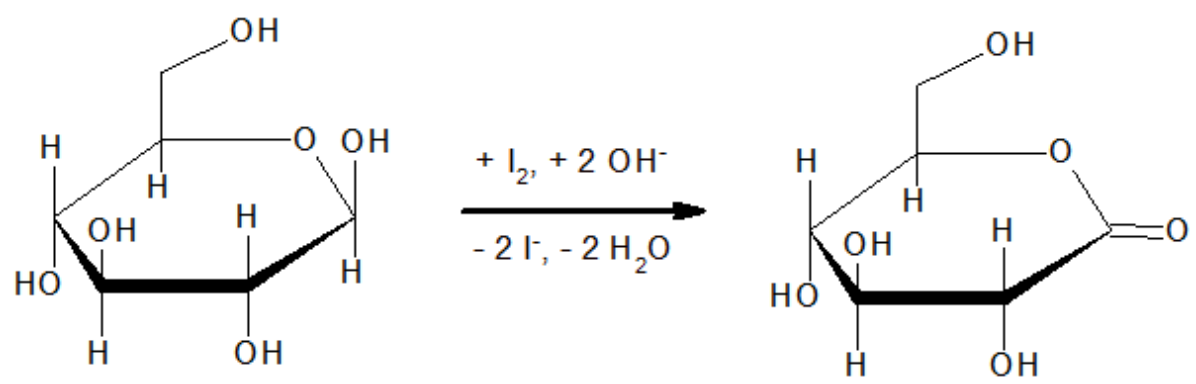

Figure 5. Simplified reaction equation for the oxidation of reducing sugars D-glucopyranose by the iodine test solution
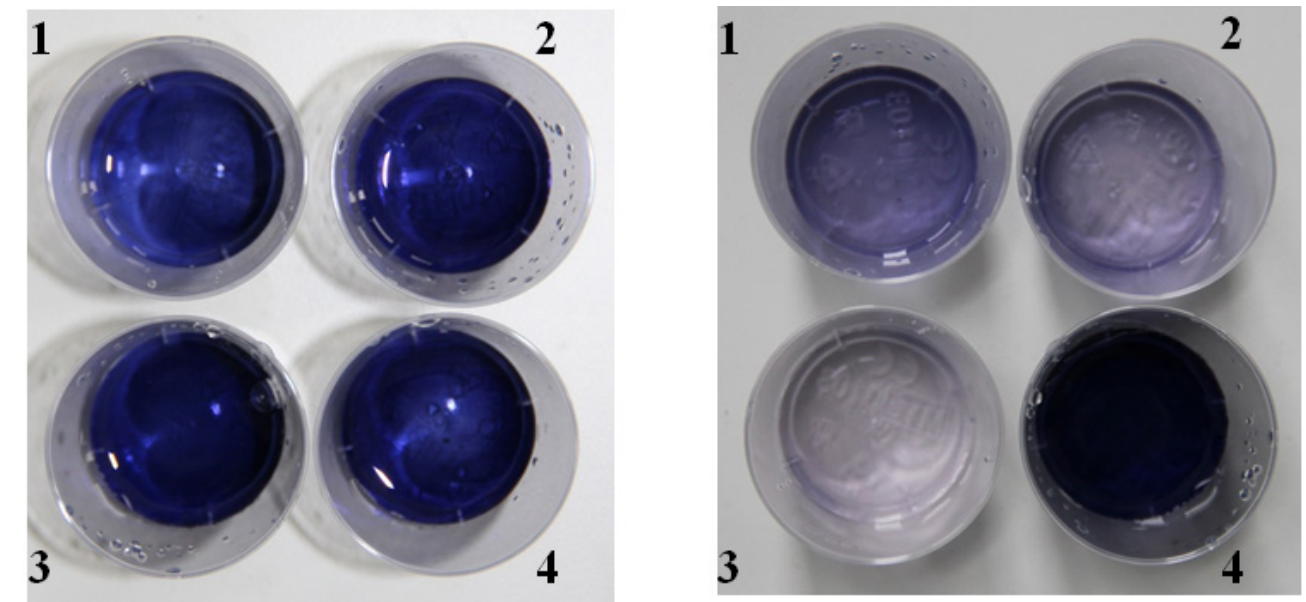

Figure 6. Mixtures of the iodine test solution with carbohydrates 1 - 4. Left: Immediately after addition to iodine test solution. Right: 30 seconds after mixing of the solutions 
Experiment 4: Lemonade - does it really contain sucrose? Lemonade tastes sweet because sucrose was added during the production process. Students know sucrose as a non-reducing carbohydrate and should thus be surprise that lemonade gives a positive iodine test. Of course, lemonade contains other ingredients as well. Most of them contain flavouring and colouring compounds and citric acid, some may contain ascorbic acid. The latter is known to reduce iodine to iodide - but this reaction proceeds already quick in neutral or weakly acidic solutions. Reducing sugars and ascorbic acid could hence be distinguished by reaction with iodine test solution at different $\mathrm{pH}$, removing the latter first by this reaction.

At this stage, students should become familiar with the

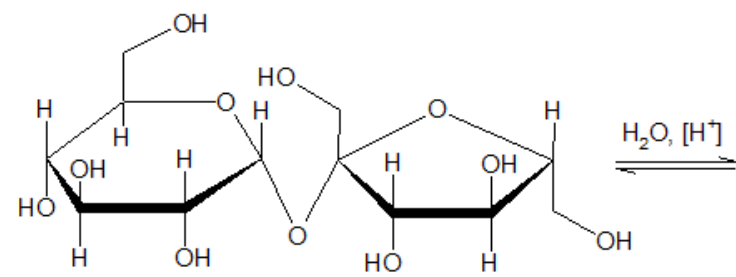

hydrolysis of the glycosidic bond, a reaction catalysed by protons (see Figure 7).

The equilibrium of this reaction is shifted towards the right side. Since lemonades are acidic solutions, they contain a suitably high concentration of protons. Hence, if sucrose was added in the production stage of the lemonade, it has been hydrolysed to give glucose and fructose. Mainly glucose is responsible for the positive iodine test. Fructose has to isomerize to glucose before (see Experiment 7), so its contribution is only of minor importance. Since the acid in the lemonade lowers the $\mathrm{pH}$ of the iodine test solution, only little lemonade should be used. As well, a 0,25 molar solution of sodium carbonat can be substituted for the buffer solution.

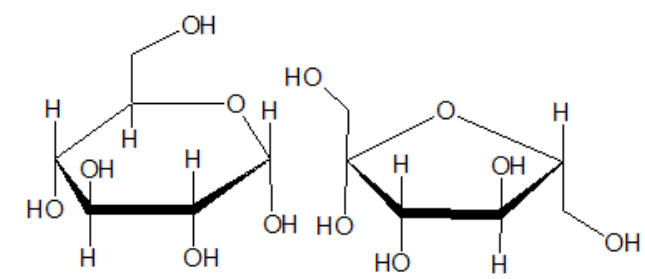

Figure 7. Hydrolytic cleavage of the glycosidic bond in the sucrose molecule, leading to the formation of glucose and fructose
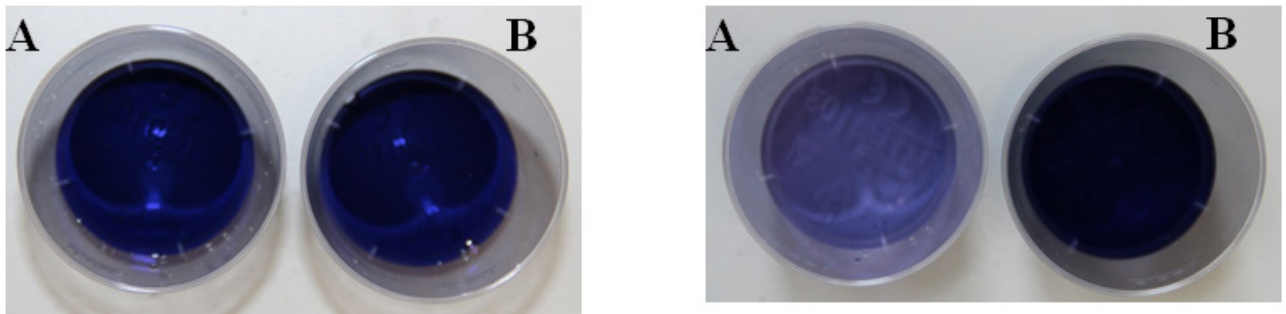

Figure 8. The iodine test with regular lemonade (A) and sugar-free lemonade (B). Left: just after lemonade was added. Right: after 4 minutes
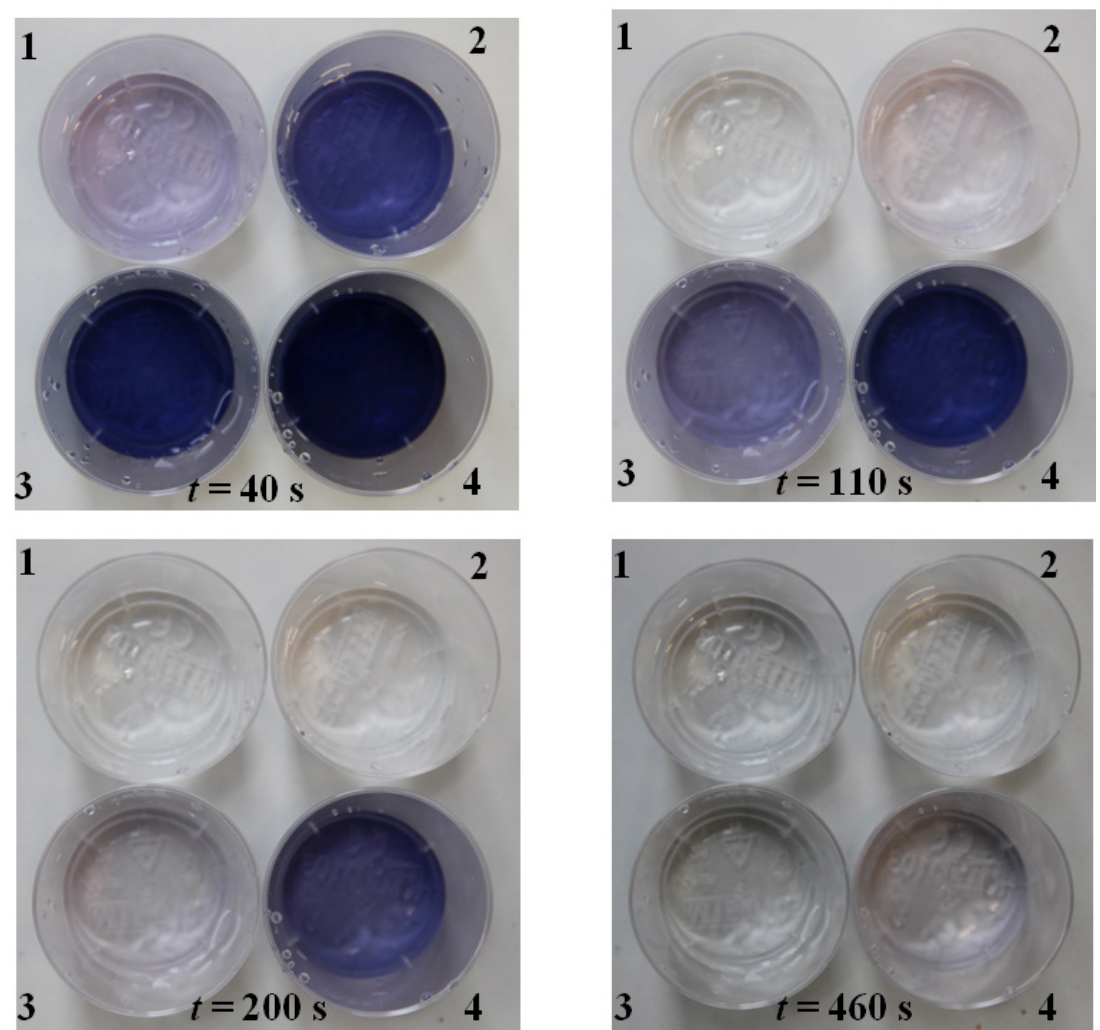

Figure 9. Alkaline iodine-starch-solutions to which equal volume of glucose solutions with different concentrations were added. The pictures show different stages of the reaction (times as indicated). (1) $c(\mathrm{glu})=0,5 \mathrm{~mol} \cdot \mathrm{L}^{-1} ;(2) c(\mathrm{glu})=0,2 \mathrm{~mol} \cdot \mathrm{L}^{-1} ;(3) c(\mathrm{glu})=0,1 \mathrm{~mol} \cdot \mathrm{L}^{-1},(4) c(\mathrm{glu})=0,05 \mathrm{~mol} \cdot \mathrm{L}^{-1}$ 
"Sugar-free lemonade" can be tested, too, and a comparison to lemonade will give a similar result as for the chewing gums (see Figure 8 and Figure 2).

Experiment 5: Concentration and the rate of reaction. The rate at which the oxidation of the reducing sugar proceeds can be qualitatively estimated by the time it takes the colour of the iodine-starch-solution to disappear. [17] (see Figure 9) Thus, apart from being a probe for reducing sugars, the iodine test can help to understand factors ruling the rate of a reaction. A higher concentration of glucose leads to a quicker disappearance of the colour of the iodine-starch-solution. If $\mathrm{c}_{0}\left(\mathrm{I}_{2}\right)$ is the starting concentration of iodine in the test solution and $\Delta \mathrm{t}$ is the time it takes the solution to become colourless, $\Delta \mathrm{c}_{0}\left(\mathrm{I}_{2}\right) / \Delta \mathrm{t}$ is a measure for the reaction rate. $\mathrm{c}_{0}\left(\mathrm{I}_{2}\right)$ being held constant, the rate increases, if $\Delta \mathrm{t}$ becomes smaller. The observations made can be rationalized in terms of a simple collision theory with respect to the concentration of glucose. The more glucose molecules are in the solution, the higher is the probability for a reactive collision with a molecule of hypoiodous acid (or iodine in a simpler view of the reaction). Nevertheless, $\Delta t$ as defined above cannot be measured objectively. In order to obtain reliable values for the rate of the reaction, the course of the reaction has to be followed by photometry. [17]
Experiment 6: Temperature and the rate of reaction. Regarding the influence of temperature, a straightforward observation is the time $\Delta \mathrm{t}$ becoming shorter with increasing temperature. An increase in temperature of $10 \mathrm{~K}$ reduced the time needed for the colour to disappear approximately to one forth. (see Figure 10). The exponential temperature dependence found can be understood in terms of the Arrhenius equation: $\mathrm{k}(\mathrm{T})=\mathrm{A} \cdot \exp \left(-\mathrm{E}_{\mathrm{A}} / \mathrm{R} \cdot T\right)$, where $\mathrm{k}(\mathrm{T})$ is the rate temperature dependent rate constant, $\mathrm{A}$ is the collision factor, $E_{\mathrm{A}}$ is the molar activation energy, $\mathrm{R}$ is the gas constant and $\mathrm{T}$ the absolute temperature.

Measuring the rate constant at different temperatures allows an estimation of the energy of activation. Details of this approach will be given in another paper. [17]

Experiment 7: If fructose is added to a weakly alkaline solution of iodine and starch, the blue colour of the solution disappears as well - much slower though than with glucose (see Figure 12). This is a surprising observation, since fructose is a ketose and cannot form a hemiacetal that can be oxidised to a lactone. The positive iodine test and its reduced rate can be rationalized in terms of the DE BRUYN-VAN EKENSTEIN-rearrangement (see Figure 11). [15]
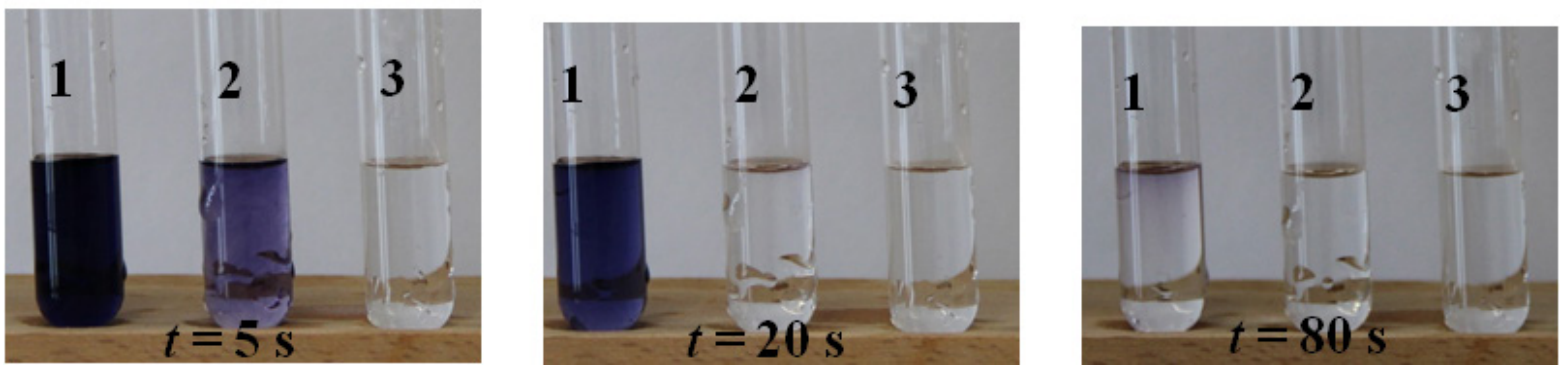

Figure 10. Alkaline iodine-starch-glucose-solutions of equal concentrations at different temperatures. (times as indicated). (1) $\mathrm{T}=293 \mathrm{~K}$, (2) $\mathrm{T}=303 \mathrm{~K}$, (3) $\mathrm{T}=313 \mathrm{~K}$

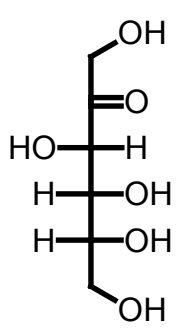

(1)
$(1)$
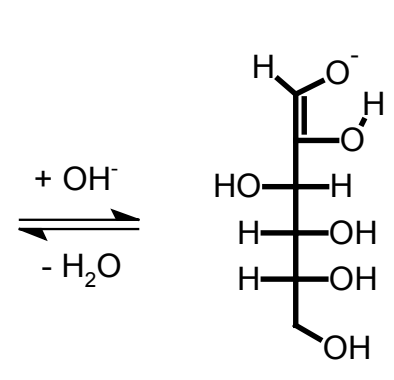

(4)
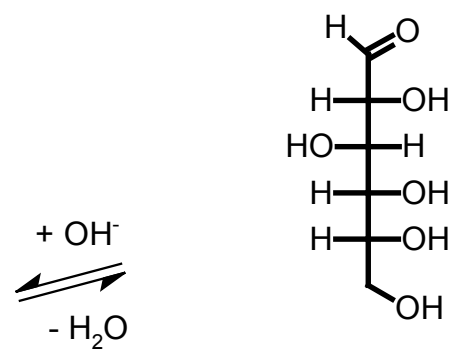

(2)

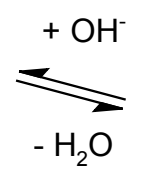

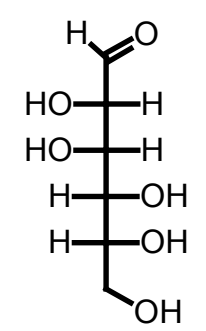

(3)

Figure 11. DE BRUYN-VAN EKENSTEIN-rearrangement between fructose (1), glucose (2) and mannose (3) via the common endiolate-form (4) 

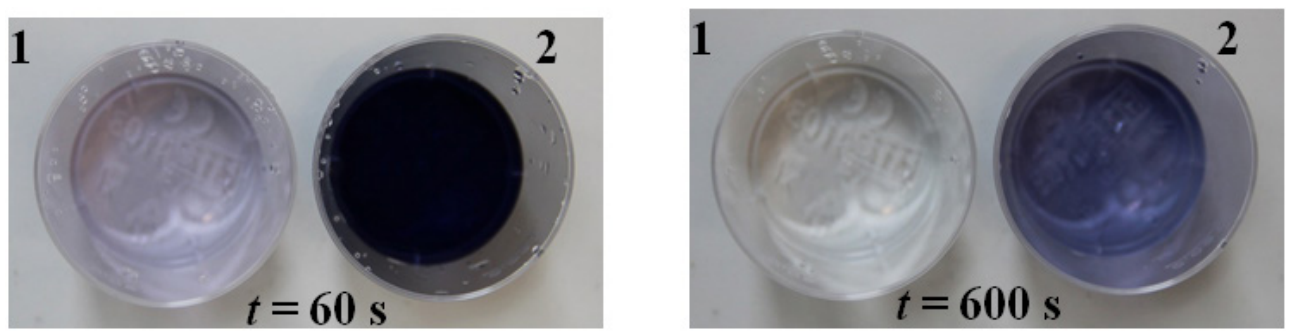

Figure 12. Comparison between equally concentrated solutions of D-glucose (1) and D-fructose (2) with respect to the iodine test. Times as indicated

In alkaline solution, fructose (1) can be transformed either to glucose (2) or mannose (3), the reaction proceeding via the endiolate ion (4). Hence aldoses are produced, which subsequently can be oxidised by the hypoiodous acid. A comparison of D-glucose and Dfructose demonstrates, that this transformation proceeds rather slow (see Figure 12).

\section{Experimental}

\subsection{Preparation of Solutions}

The three solutions necessary for the iodine-test, subsequently named A, B and C, were prepared as follows:

Solution A: Aqueous solution of iodine $\left(\mathrm{c}\left(\mathrm{I}_{2}\right)=0,001\right.$ $\left.\mathrm{mol} \cdot \mathrm{L}^{-1}\right)$ and potassium iodide $\left(\mathrm{c}(\mathrm{KI})=0,01 \mathrm{~mol} \cdot \mathrm{L}^{-1}\right)$. Iodine, $\mathrm{I}_{2},(\mathrm{~m}=0,254 \mathrm{~g})$ and potassium iodide, $\mathrm{KI},(\mathrm{m}=$ $1,660 \mathrm{~g}$ ) were dissolved in demineralised water in a sealed Erlenmeyer flask. The solution was then filled up to $\mathrm{V}=$ $1000 \mathrm{~mL}$ in a standard measuring flask.

Solution B: Buffer solution of sodium carbonate $\left(\mathrm{c}\left(\mathrm{Na}_{2} \mathrm{CO}_{3}\right)=0,25 \mathrm{~mol} \cdot \mathrm{L}^{-1}\right)$ and sodium bicarbonate $\left(\mathrm{c}\left(\mathrm{NaHCO}_{3}\right)=0,25 \mathrm{~mol} \cdot \mathrm{L}^{-1}\right)$. Anhydrous sodium carbonate, $\mathrm{Na}_{2} \mathrm{CO}_{3}(\mathrm{~m}=26,50 \mathrm{~g})$, and sodium bicarbonate, $\mathrm{NaHCO}_{3}(\mathrm{~m}=21,00 \mathrm{~g})$ were dissolved in demineralised water. The solution was then filled up to $\mathrm{V}=1000 \mathrm{~mL}$ in a measuring flask.

Solution C: Starch solution $(\mathrm{w}(\mathrm{starch})=0,1 \%)$. In a beaker, water was added to soluble starch $(\mathrm{m}=0,1 \mathrm{~g})$ until the mass of the mixture summed up to $100,0 \mathrm{~g}$. The mixture was heated in a microwave oven until the starch dissolved. The hot solution was filled in a $100 \mathrm{~mL}$ dropping bottle, sealed and cooled in a water bath.

Solutions of D-glucose (experiments 5 to 7) and D-fructose (experiment 7), were prepared as follows:

Solution of D-glucose $\left(\mathrm{c}=0,5 \mathrm{~mol} \cdot \mathrm{L}^{-1}\right)$. D-glucosemonohydrate, $\mathrm{C}_{6} \mathrm{H}_{12} \mathrm{O}_{6} \cdot \mathrm{H}_{2} \mathrm{O}(\mathrm{m}=9,90 \mathrm{~g})$ was dissolved in water. The solution was then filled up to $\mathrm{V}=100 \mathrm{~mL}$ in a measuring flask.

Solution of D-glucose $\left(\mathrm{c}=0,2 \mathrm{~mol} \cdot \mathrm{L}^{-1}\right) .40 \mathrm{~mL}$ of the glucose-solution $\left(\mathrm{c}=0,5 \mathrm{~mol} \cdot \mathrm{L}^{-1}\right)$ were filled up to $\mathrm{V}=100 \mathrm{~mL}$ in a measuring flask.

Solution of D-glucose $\left(\mathrm{c}=0,1 \mathrm{~mol} \cdot \mathrm{L}^{-1}\right) .50 \mathrm{~mL}$ of the glucose-solution $\left(\mathrm{c}=0,2 \mathrm{~mol} \cdot \mathrm{L}^{-1}\right)$ were filled up to $\mathrm{V}=100 \mathrm{~mL}$ in a measuring flask.

Solution of D-glucose $\left(\mathrm{c}=0,05 \mathrm{~mol} \cdot \mathrm{L}^{-1}\right) .50 \mathrm{~mL}$ of the glucose-solution $\left(\mathrm{c}=0,1 \mathrm{~mol} \cdot \mathrm{L}^{-1}\right)$ were filled up to $\mathrm{V}=100 \mathrm{~mL}$ in a measuring flask.

Solution of D-fructose $\left(\mathrm{c}=0,5 \mathrm{~mol} \cdot \mathrm{L}^{-1}\right)$. D-Fructose, $\mathrm{C}_{6} \mathrm{H}_{12} \mathrm{O}_{6}(\mathrm{~m}=9,00 \mathrm{~g})$ was dissolved in water. The solution was then filled up to $\mathrm{V}=100 \mathrm{~mL}$ in a measuring flask.

\subsection{Experimental Procedures}

General procedure: If not stated otherwise, for each test, $1,0 \mathrm{~mL}$ of each of the solutions $\mathrm{A}, \mathrm{B}$ and $\mathrm{C}$ were mixed in a small plastic beaker $(20 \mathrm{~mL})$.

Experiment 1: Two beakers with test solutions were prepared. To one of the solutions, a slice of approximately $1 \mathrm{~cm}$ length cut from a sugar-containing chewing gum was added. An equally sized slice of a sugar-free chewing gum was added to the other solution. The mixtures were steadily tossed carefully and observed for changes in colour during five minutes.

Experiment 2: Three beakers with test solutions were prepared. A grape is cut in half. The two halves are squeezed between two spoons and the juice thus release is collected in a forth beaker. Pea-sized amounts of table sugar (sucrose) and grape sugar (glucose), respectively, are added to two of the beakers. They are at least partially dissolved by slightly tossing the beakers. The grape juice is added to the third beaker. The mixtures were observed for changes in colour occurring within a few seconds.

Experiment 3: Four beakers with test solutions were prepared. Pea-sized amounts of D-glucose (1), D-galactose (2), maltose (3) and sucrose (4) were added. The solids are at least partially dissolved by slightly tossing the beakers. The mixtures were observed for changes in colour occurring within a few seconds.

Experiment 4: Since lemonade is an acid solution, the volume of the buffer solution here is $2 \mathrm{~mL}$ instead of 1 $\mathrm{mL}$ for each test solution. Two beakers with test solutions were prepared. Five drops of "regular", sugar containing lemonade and sugar-free lemonade, respectively, are added. The mixtures were observed for changes in colour occurring within a few minutes.

Experiment 5: Four beakers with test solutions were prepared. Then, simultaneously $1,0 \mathrm{~mL}$ of D-glucosesolutions with concentrations $0,5 \mathrm{~mol} \cdot \mathrm{L}^{-1}, 0,2 \mathrm{~mol} \cdot \mathrm{L}^{-1}$, $0,1 \mathrm{~mol} \cdot \mathrm{L}^{-1}$ and $0,05 \mathrm{~mol} \cdot \mathrm{L}^{-1}$ were added. The time, when the colour seems to disappear was measured.

Experiment 6: Three test tubes were filled with the iodine-test solution. Three more test tubes were filled with a solution of D-glucose $\left(\mathrm{c}=0,5 \mathrm{~mol} \cdot \mathrm{L}^{-1}\right)$. Their temperatures were set to $293 \mathrm{~K}, 303 \mathrm{~K}$ and $313 \mathrm{~K}$, respectively, by putting them for five minutes into appropriate water baths and shaking the tubes occasionally. $1,0 \mathrm{~mL}$ of the D-glucose-solution was simultaneously added to the test-solution with the same temperature. The time, when the colour seems to disappear was measured.

Experiment 7: Two beakers with test solutions were prepared. Then, simultaneously $1,0 \mathrm{~mL}$ of D-glucose- and D-fructose-solutions with concentrations of $0,5 \mathrm{~mol} \cdot \mathrm{L}^{-1}$, were added. The time, when the colour of either seems to disappear was measured. 


\section{References}

[1] James, G., Mastersson, N., McWhinnie, J.-A., Hickling, B., Healthy eating. Curriculum Kit for South Australian Primary Schools, Government of South Australia 2013.

[2] Aston, T.-A., The really useful book of science experiments; Rootledge, New York, 2016, p. 20.

[3] Elzagheid, M.I., Laboratory Activities to Introduce Carbohydrates Qualitative Analysis to College Students. World Journal of Chemical Education, 6(2), 82-86, 2018.

[4] Fleischer, H., False Interpretation of Fehling's Test for Reducing Sugars - From Observation in the Lab to Evidence against an Aldehyde Oxidation. CHEMKON, 24(1), 27-30, 2017.

[5] Stojanovska, M. Šoptrajanov, B., Petruševski, V. M., Misconceptions in the Chemistry Teaching in the Republic of Macedonia Regarding the Oxidation Reactions of Monosaccharides. Contributions, Sec. Nat. Math. Biotech. Sci., 34 (1-2), 27-32, 2013.

[6] Amick, C. A., The Copper Number of Glucose, J. Phys. Chem., 31, 1441-1477, 1927.

[7] Evans, W. L., Nicoll, W. D., Strous, G. C., Waring, E., The Mechanism of Carbohydrate Oxidation. IX. The Action of Copper
Acetate Solution on Glucose, Fructose and Galactose. J. Am. Chem. Soc. 50, 2267-2285, 1928.

[8] Scherz, H., On the mechanism of the Fehling Reaction. Z Lebensm. Unters. Forsch., 168, 91-98, 1979.

[9] Daniels, R, Rush, C.C., Bauer L., The Fehling and Benedict Test. J. Chem. Edu., 37(4), 205, 1960.

[10] Willstädter, R., Schudel, G., Bestimmung von Traubenzucker mit Hypojodit. Ber. dtsch. chem. Ges. 51, 780-781, 1918.

[11] Goebel, W. F., On the Oxidation of Glucose in Alkaline Solutions of Iodine. J. Biol. Chem. 72, 801-807, 1927.

[12] Ingles, O. G. Israel, G. C., The Oxidation of Some Aldoses by Alkaline Solutions of Iodine. J. Chem. Soc. 810-814. 1948.

[13] Ingles, O. G., Israel, G. C., The Oxidation of Aldoses by Hypoiodous Acid. J. Chem. Soc. 1213-1216, 1949.

[14] Mehltretter, C. L., Some Landmarks in the Chemical Technology of Carbohydrate Oxidation. Die Stärke, 15(9), 313-319, 1963.

[15] Evans, W. L. Some less Familiar Aspects of Carbohydrate Chemistry. Chem. Rev. 31, 537-560, (1942).

[16] Wadsworth, B., J. Piaget's theory of cognitive and affective development: Foundations of constructivism (5th ed.). White Plains, NY, England: Longman Publishing. (1996).

[17] Fleischer, H., Quantitative determination of glucose by the iodinetest. Manuscript in preparation. 